\title{
INFLUENCE OF THE THREE LINKS AGREEMENT ON THE BEHAVIOR OF TAIWAN AIRPORTS: A TWO-STAGE DEA ANALYSIS
}

\author{
Lu Yang ${ }^{1}$
}

\section{ABSTRACT}

Taiwan is a small island with a relatively large number of airports. These airports show great disparity in terms of passenger volume and cargo tonnage. This paper in the first part evaluates the efficiency and productivity of Taiwanese airports using a panel data set, to verify the ones with lower efficiency performances. DEA (Data Envelopment Analysis) and Malmquist index methods are applied. In the second stage the changes of these scores are analyzed in different regression methods to test the influence of the Three Link agreement between China and Taiwan. It reveals that airports in Taiwan with routes to China have lower efficiency scores but their productivity grows faster than that of the other airports. This paper also confirmed that airports on offshore islands have higher efficiency scores and productivity.

\section{KEYWORDS}

DEA; Malmquist index; Airport benchmarking

\footnotetext{
${ }^{1}$ Policy Analysis Program, National Graduate Institute for Policy Studies, Tokyo, Japan. Phd11105@grips.ac.jp +81-80-46870321
} 


\section{INTRODUCTION}

Taiwan is an island off the southeast coast of mainland China, facing the Pacific in the other side, consisting of a main Taiwan Island and several offshore islands. Taiwan has a natural advantage in international aeronautic transportation in the Asia-Pacific region: it is only 90 minutes away from Hong Kong and even less time to Shanghai by air. The flight time it costs from Taipei to Seoul and Tokyo are 140 minutes and 180 minutes respectively. Within 3 to 4 hours, one can reach Bangkok and Singapore from Taipei easily, enough for a one-day business trip. In its economic development history, there used to be a huge aviation demand that came along with the Taiwanese economic taking off during the 1970s, when more than one third of the civil aviation airports in Taiwan were built. Partly because of this convenient location between East Asia and Southeast Asia, also because of a great aviation demand in its economic development history, Taiwan has quite an extraordinarily high level of airport density. In Figure 1 we list the airport density of major countries/regions around the world. The information of commercial airports is collected from the official websites of each country's Civil Aviation Authority or the Department of Transportation. We can see that Taiwan ranks top in these selected countries/regions.

Figure 1: Worldwide Airport Density

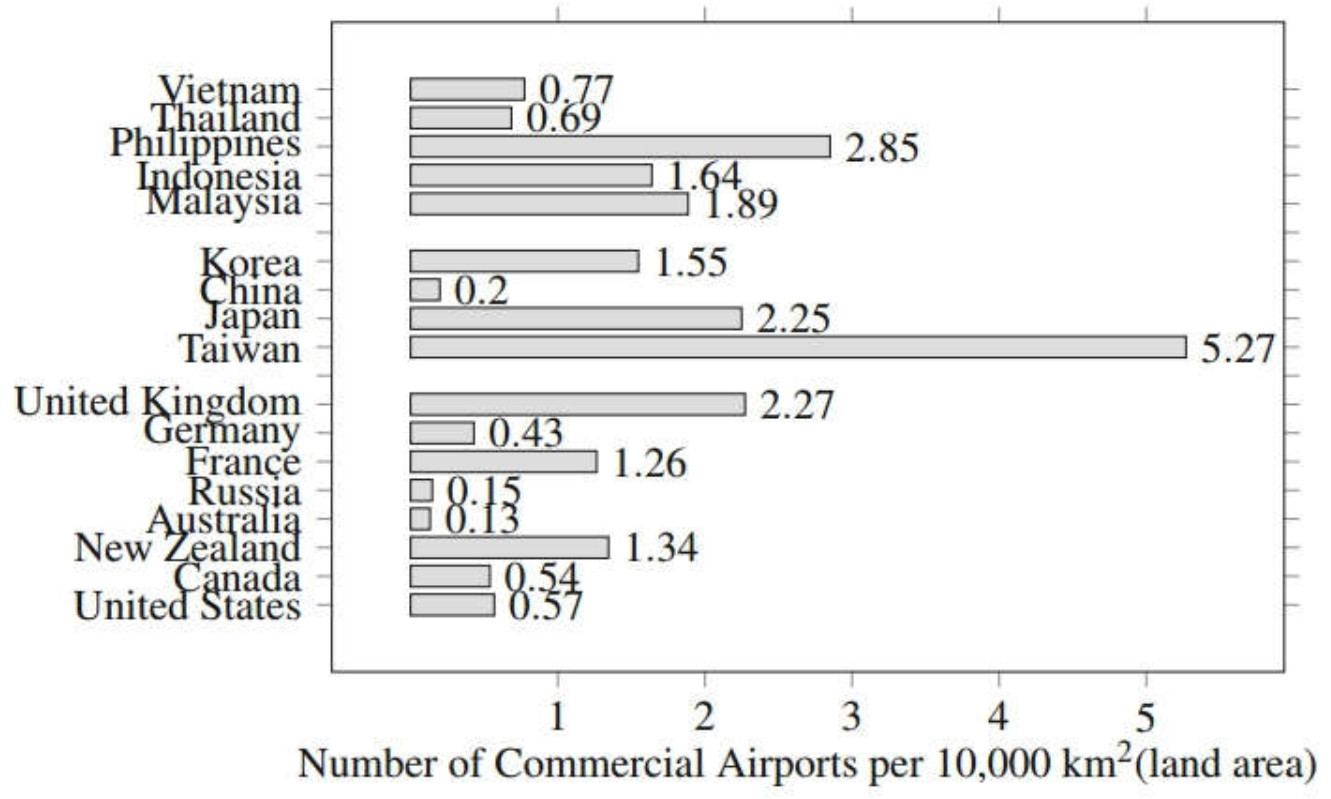

However, the total aviation passenger number as well as cargo tonnage have been on the decline since the year 1997 (with some exception years), along with the decelerated economic growth. The trend of Taiwanese aviation demand in recent forty 
years is shown in Figure 2. This decline continued in domestic flights when THSR ${ }^{2}$ opened for service in 2007. However, as we can see in Figure 2, despite the fact that the domestic aviation demand decreased rapidly after around 1996, the international aviation passengers number kept growing.

More importantly, Taiwanese airports experienced a big change last decade, when the "Three Links" agreement was signed between mainland China and Taiwan. "Three Links" stands for direct postal service, direct transportation and direct trade between mainland China and Taiwan, which put an end to the history of no traffic relations between PRC China and ROC Taiwan since the end of the Chinese Civil War in 1949. The first chartered flight between mainland China and Taiwan appeared in 2003, when the flights had to make a transit in Hong Kong or Macau, and the airplane could only make one-way flight during traditional Chinese festival periods. After the huge earthquake in Sichuan, China in May 2008, humanity chartered flights were permitted for Taiwanese relief supplies ${ }^{3}$ and rescue teams ${ }^{4}$ to be sent directly to the disaster area. Two months later on July 4th 2008, first weekend regular chartered cross-strait flight made its debut without stopping by Hong Kong ${ }^{5}$, although a symbolic passing through the Hong Kong FIR (Flight Information Region) was still necessary. Finally, at the end of 2008, the regular daily flights across Taiwan Strait without detouring over Hong Kong came into reality ${ }^{6}$.

\footnotetext{
2 Taiwan High Speed Rail. Currently runs from Taipei to Zuoying (Kaohsiung).

${ }^{3}$ Chinese Airlines chartered cargo plane will make a direct flight to Sichuan in the afternoon to deliver relief supplies (in Chinese). RTHK. May 15, 2008. http://www.rthk.org.hk/rthk/news/expressnews/20080515/news $\measuredangle 20080515\lfloor 55\lfloor 490$ 111.htm

${ }^{4}$ The Mainland agrees to receive 20 members of our Red Cross Society's relief team to join the relief effort --- due to arrive in Chengdu by charter plane in the afternoon of the 16t (in Chinese). The Red Cross Society of the Republic of China. May 15, 2008. http://www.redcross.org.tw/RedCross/upload/main/00-2008hqrcyteam/970515.htm

5 Taipei, Beijing reach historic pact. The China Post \& agencies. June 13, 2008 http://www.chinapost.com.tw/taiwan/china-taiwanrelations/2008/06/13/160749/Taipei-Beijing.htm ${ }^{6}$ Direct cross-strait links in place. The China Post. December 15, 2008 http://www.chinapost.com.tw/taiwan/china-taiwanrelations/2008/12/15/187643/p2/Direct-cross-strait.htm
} 
Figure 2: Taiwan's Aviation Passenger ${ }^{7}$

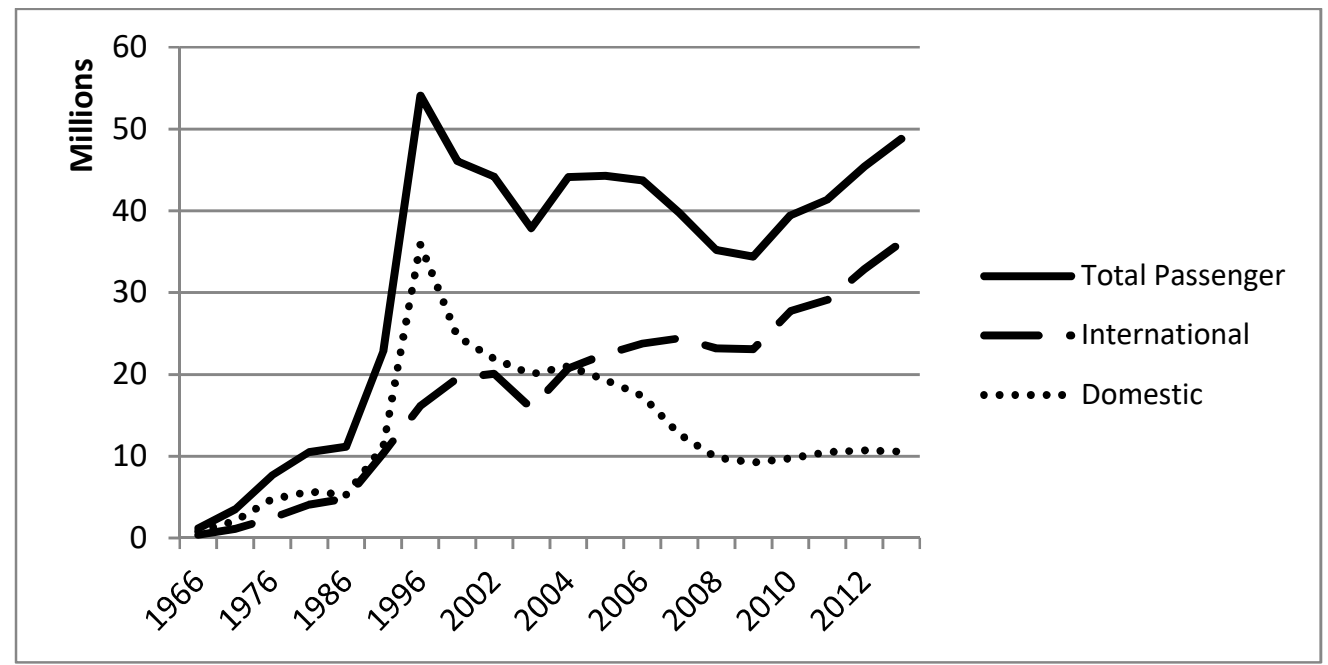

It would be interesting to see how the policy change by the Three Links Agreements affects the efficiency and productivity of airports from both China and Taiwan. We focus on the behavior of Taiwanese airports in this paper. From Figure 2 the year 2009 appears to be a watershed: the growth of international aviation demand sped up and the domestic aviation demand stopped decreasing and increased slightly in recent years. As a whole the total aviation demand of Taiwan finished its 10 years decrease and returned to a strong increase ever since. Despite of the influence of the financial crisis of 2007-2008 and the bankrupt of Lehman Brothers, which pulled down the growth rate of Taiwan's GDP to around $-5 \%{ }^{8}$, along with the opening of THSR, both domestic and international passenger volume have better performance since 2009 than before. Our hypothesis in this paper is that the opening of direct China air route plays an important role. To evaluate the efficiency difference, we define efficiency by the DEA efficiency scores and productivity change by Malmquist index. DEA scores measure the relative ratio of (weighted) output to input of a specific DMU (Decision Making Unit) while Malmquist index evaluates the productivity change of one DMU between two time periods. The detail will be discussed in section 2.2 , where the overall efficiency and productivity will be compared before and after the Three Link agreement. As it is widely discussed within Taiwan about whether small local airports should be open to direct China routes, our interest also lies in the possible gap between big airports like Taoyuan airport and small airports like Hengchun airports, after the Three Link agreement.

\footnotetext{
7 Data source: Traffic of Civil Aviation by Airports: http://www.caa.gov.tw/en/content/index.asp?sno=362

8 Taiwan GDP Growth Rate. http://www.tradingeconomics.com/taiwan/gdp-growth. Trading Economics
} 
The remainder of this paper unfolds as follows. In the next section, we will introduce the development of DEA in airport benchmarking. In section 2, I will introduce the methodology applied in this study. In section 3 we are trying to measure (1) the efficiency of Taiwan airports; (2) the technical efficiency change (TEC) and the frontier shift (FS) of Taiwan airports over the years 2004 to 2011. Furthermore, we are going to analyze the impact of this policy change not only on the efficiency (DEA score) but also on the productivity change (Malmquist Index) of airports. A second stage panel data regression will be adopted to check the impact of endogenous factors of the airports, especially the effect of the Three Links Agreement between China and Taiwan. The results and conclusion, as well as policy suggestions, will constitute the last section.

\section{LITERATURE REVIEW}

The efficiency of airports has long been measured and evaluated in a wide variety of contexts. Among those methods DEA is one of the most widely used ones. In fact, in the appendices of Liebert and Niemeier's survey of empirical studies on the productivity and efficiency of airports (Liebert \& Niemeier, 2013), only 4 studies employ price-based index approaches, 20 papers applied parametric approaches (SFA: Stochastic frontier analysis, is the main approach), while 37 papers use non-parametric approaches. Among those non-parametric papers 30 apply DEA purely and 6 compare DEA results to those of other methods. DEA method is chosen in many empirical studies because of its advantage in dealing with the naturally complex relation among multiple inputs and outputs of the DMUs, which is difficult to deal with other methodologies. In DEA models there is no assumption on a functional form for the DMUs and the production process is seen as being operated in a black box. For example, when measuring Taiwan's domestic airport efficiency, Yu (2004) applied DEA analysis with one undesirable output (airplane noise) and population of the prefecture where the airport locates is introduced as an environmental variable. The economical cost of the airplane noise or the mechanism it affects airports' operation is not necessary in DEA and the weight for each input or output is decided individually.

In the field of airport benchmarking, there is a significant amount of studies done by various researchers. Yoshida and Fujimoto (2004) calculated both the CRS and VRS efficiency scores of Japanese airports in year 2000. In the second stage they conducted a Tobit regression to test the connection between the efficiency scores and 
two factors indicating the characteristics of each airport. Abbott and Wu (2002) analyzed both the total factor productivity (Malmquist Index) for twelve Australian airports and technical efficiency (DEA efficiency score) for Australian and international airports. Malmquist Index is decomposed into technical efficiency change and technological change, technical efficiency change is further decomposed into pure technical efficiency and scale efficiency. A second stage regression is also applied.

For the efficiency of Taiwan airports, the previous studies are quite limited. Some research compared the efficiency of global airports and TPE (Taoyuan International Airport) is included as one of the research objects. For example, Oum and Yu (2004) measured and compared the Variable Factor Productivities (VFP) of 76 major airports including TPE, utilizing the data from the 2003 ATRS global airport benchmarking report. VFP is chosen in this study because of the lack of information on the capital input of each airport and the distortion caused by government subsidy on airport capital expansion projects. TPE is also included in Yang's research (2010) on twelve international airports of the Asia-Pacific area from 1998 to 2006. DEA and SFA are both used in his study and the relations between the results of the two methods are discussed. Lin and Hong (2006) calculated the DEA efficiency score for twenty airports around the world by both CCR and BCC model. Besides the undesirable output study (Yu, 2004), Yu, Hsu, Chang, and Lee (2008) applied Malmquist-Luenberger productivity index and window approach to a panel data of four domestic airports of Taiwan, for a period from 1995 to 1999. Yu (2010) also conducted a cross section research on the fifteen domestic airports of Taiwan in the year 2006, using a slacks-based measure network DEA (SBM-NDEA) model.

In the Taiwan airport case, we not only want to obtain the efficiency scores for each airport, but also more importantly we are eager to identify the possible influence brought to the efficiency and productivity of Taiwanese airport by the Three Link agreement. At first, we would like to distinguish the performance of Taiwanese airports before and after the specific year when a China route was opened. If we want to know how the efficiency and productivity of DMUs changes during a specific time period, the Malmquist Index is a proper indicator which is calculated based on DEA efficiency scores of each year. Two stage Malmquist Index analyses are rarely seen in airport benchmarking. Fung, Wan, Hui, and Law (2008) evaluated the efficiency scores and Malmquist productivity for twenty-five Chinese airports during year 1995-2004. In the 
second stage, however, they did not use a regression but only showed the $\mathrm{ODF}^{9}$ by groups to explain the relation between the airports' productivity and other factors such as the location or ownership of the airports. In this paper SBM DEA and Malmquist index model are applied for all the Taiwanese airports for a time span across the signing of Three Link agreement, also a second stage regression is run to verify the effect on efficiency and productivity of airports by China air routes or other characteristic factors.

\section{DATA AND MODELS}

\section{Data}

We collect the data of eighteen airports used in this study from the website of Civil Aeronautics Administration, Republic of China ${ }^{10}$. The biggest Taoyuan International Airport is operated by a state-owned cooperation. All the rest seventeen airports are administrated by the Civil Aeronautics Administration. It is a balanced panel data from year 2004 to year 2011. This is the longest time period given data availability and the fact that Hengchun Airport started its operation in the new terminal since Dec. 2003 and that Pingdong Airport finished its run in the year 2012. We have three variables each for input and output. The annual volume of Passenger, Cargo and Taking-off and landings are output variables. Terminal area, runway area and apron areas are input variables. Labor input is not included in this study because of data availability. This is not a big issue as we only focus on the capital input productivity.

There is a giant gap in the inputs and outputs among Taiwanese airports, while the changes along the eight years in each airport are not so significant. If we look at the input variables in the year 2011, we can find that the terminal area of Taoyuan International Airport accounts for nearly $80 \%$ of the total terminal area of the nineteen airports. Correspondingly, its apron area accounts for more than half of the total apron area. For runway area it is not so extreme but still Taoyuan runway accounts for $20 \%$ of the sum. The situation, as expected, is similar in the output section, where $42 \%$, $60 \%$, and $94 \%$ of the taking-off and landing, passenger volume and cargo volume are delivered by Taoyuan International Airport.

\footnotetext{
${ }^{9}$ Output Distance Functions, the terminology they adapt for DEA efficiency score.

10 http://www.caa.gov.tw/big5/content/index.asp?sno=186
} 
Taking a deeper glance at the output data, we could also find some interesting trends for different airports. For example, the passenger number of Taoyuan International Airport increases steadily until 2008, possibly due to the opening of THSR and the global recession resulted from the bankruptcy of Lehman Brothers. Both passenger volume and cargo volume recovered in 2010 though, when Taiwan economy expanded remarkably at a 23 -year high of $10.8 \%{ }^{11}$.

For the second biggest Songshan Airport located within Taipei city which mainly operates domestic flights, the recovery in 2010 is not so strong as the previous one. The passenger number fluctuates around 4 million per year, no bigger than 2008 level. Kaohsiung Airport is the second biggest international airport in Taiwan, which has a decreasing passenger volume even before the crisis. However, the recovery since 2010 seems to be strong comparing to other airports. Passenger volume of Taichung Airport and Kinmen Airport grows rapidly despite of the crisis in 2008, passenger volume in Magong Airport recovers immediately since 2009. The four airports in main Taiwan island, namely Tainan, Taitung, Chiayi and Hualien, are examples of a rapidly decreasing passenger volume, the recoveries are slow and seem to be difficult for them. The trends of passenger volume for these typical airports are listed in Figure 3 and Figure 4.

\section{Models}

Assuming variable return to scales, which is realistic for the airport case, we chose an input-oriented model because our research focus is on the necessary infrastructure of airport in accordance with demand level. In other words, aviation demand is regarded as an exogenous variable here. We are trying to find out the most efficient allocation for the airport capital investment inputs, in order to give a reference to policy makers in making the right decisions.

The original input oriented model is a radial DEA model, where a proportional change of inputs and/or outputs is dealt with. There is another non-radial DEA model too. According to Cooper, Seiford, and Tone (2007), a non-radial input-oriented slacksbased model (SBM) deals better with input slacks (excesses). In the case of this paper, all the inputs for Taiwanese airports do not change in the same scale. For example, there exists a minimum requirement for the length and width of the airstrip even in an

${ }^{11}$ National Statistics, Republic of China (Taiwan) 
airport with small passenger volume. On the other hand, we could increase the efficiency score by reducing the size of the terminal building. This kind of input slack would not affect the ordinary CCR efficiency score, though. So the Slack-Based Model (Tone, 2011) is applied to take into account all input slacks in DEA calculation.

Figure 3: Passenger Volume Trend for the Three Biggest Airports in Taiwan

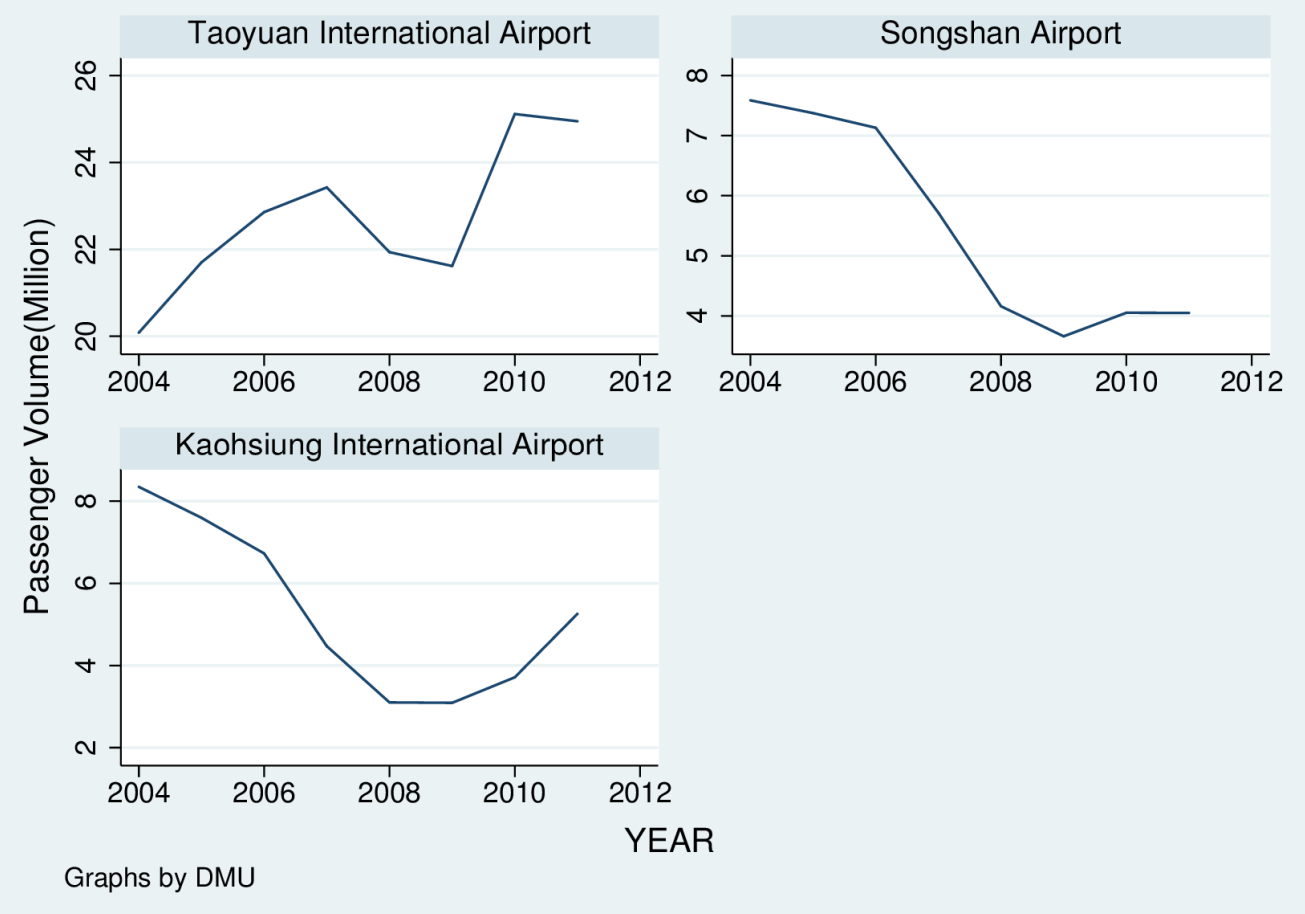

Figure 4: Passenger Volume Trend for some Typical Airports in Taiwan

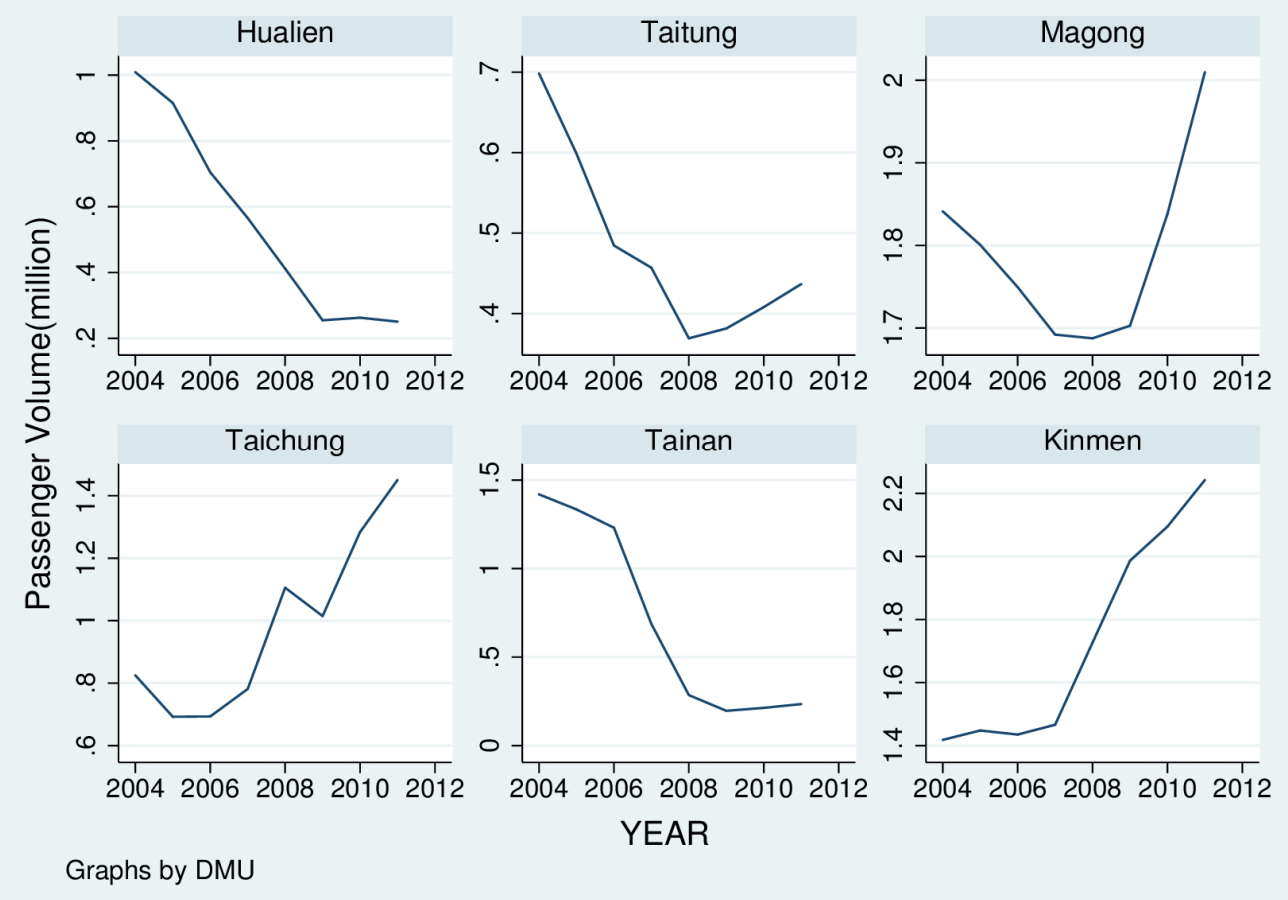


Suppose there are $n$ DMUs for which the efficiency score is calculated. For each DMU there are $m$ inputs and $s$ outputs. For a specific year, $\mathbf{X}$ and $\mathbf{Y}$ are the input and output matrices respectively. $\mathrm{s}_{\mathrm{i}}^{-}$is the slack of input $i$ for DMU $\boldsymbol{O}$ and $\boldsymbol{\lambda}$ is a non-negative vector $\boldsymbol{\lambda}=\left(\boldsymbol{\lambda}_{1}, \ldots, \boldsymbol{\lambda}_{\mathrm{n}}\right)^{\mathrm{T}}$. The efficiency value $\theta_{o}^{t}$ for DMU $O$ at time $t$ is obtained by solving the following problem:

$$
\theta_{\mathrm{o}}^{\mathrm{t}}=\min _{\lambda, \mathrm{s}^{-}}\left(1-\frac{1}{\mathrm{~m}} \sum_{\mathrm{i}=1}^{\mathrm{m}} \mathrm{s}_{\mathrm{i}}^{-} / \mathrm{x}_{\mathrm{io}}\right)
$$

Subject to

$$
\begin{gathered}
\mathrm{X}_{\mathrm{o}}=\mathrm{X} \boldsymbol{\lambda}+\mathrm{s}^{-} \\
\mathrm{y}_{\mathrm{o}} \leq \mathrm{Y} \boldsymbol{\lambda} \\
\mathrm{e} \lambda=1 \\
\lambda \geq 0, \mathrm{~s}^{-} \geq 0
\end{gathered}
$$

As we are eager to know the historical trend of Taiwanese airports' performance and how it is affected by the China factor and other characteristic variables, we apply Malmquist index calculation afterward for the productivity measurement, based on the efficiency score result of non-radial input-oriented SBM model above. Malmquist input index is developed into a productivity measurement by Fare, Grosskopf, and Lovell (1994) from the original idea of Malmquist (1953).

$$
\mathrm{M}_{\mathrm{o}}=\left[\frac{\theta_{o}^{t}\left(\mathrm{x}_{\mathrm{o}}^{\mathrm{t}+1}, \mathrm{y}_{\mathrm{o}}^{\mathrm{t}+1}\right)}{\theta_{o}^{t}\left(\mathrm{x}_{\mathrm{o}}^{\mathrm{t}}, \mathrm{y}_{\mathrm{o}}^{\mathrm{t}}\right)} * \frac{\theta_{o}^{t+1}\left(\mathrm{x}_{\mathrm{o}}^{\mathrm{t}+1}, \mathrm{y}_{\mathrm{o}}^{\mathrm{t}+1}\right)}{\theta_{o}^{t+1}\left(\mathrm{x}_{\mathrm{o}}^{\mathrm{t}}, \mathrm{y}_{\mathrm{o}}^{\mathrm{t}}\right)}\right]^{\frac{1}{2}}
$$

Here $\theta_{o}^{t}\left(\mathrm{x}_{0}^{\mathrm{t}}, \mathrm{y}_{0}^{\mathrm{t}}\right)$ calculates the above input-oriented VRS model (1), comparing the production of DMU $O$ at time $t$ to the productivity frontier at time $t . \theta_{o}^{t}\left(\mathrm{x}_{0}^{\mathrm{t}+1}, \mathrm{y}_{0}^{\mathrm{t}+1}\right)$ calculates the input-oriented VRS envelopment model, comparing the production of DMU $o$ at time $t+1$ to the productivity frontier at time $t$, respectively.

Additionally, Malmquist Index can be decomposed into two parts: catch-up and frontier-shift. Catch-up effect indicates the change in relative efficiency of a specific DMU from period $t$ to period $t+1$; Frontier-shift effect indicates the change in the frontier technology around a specific DMU from period $\mathrm{t}$ to period $\mathrm{t}+1$.

$$
\mathrm{M}_{\mathrm{o}}=C U * F S
$$




$$
\begin{gathered}
C U=\frac{\theta^{t+1}\left(x_{0}^{t+1}, y_{0}^{t+1}\right)}{\theta^{t\left(x_{0}^{t}, y_{0}^{t}\right)}} \\
F S=\sqrt{\frac{\theta^{t}\left(x_{0}^{t}, y_{0}^{t}\right)}{\theta^{t+1}\left(x_{0}^{t}, y_{0}^{t}\right)} * \frac{\theta^{t}\left(x_{0}^{t+1}, y_{0}^{t+1}\right)}{\theta^{t+1}\left(x_{0}^{t+1}, y_{0}^{t+1}\right)}}
\end{gathered}
$$

where CU stands for catch-up effect and FS stands for frontier-shift effect.

\section{RESULTS}

We use DEA-Solver (Version 10.0) to calculate the DEA efficiency score and Malmquist index. The results are listed in section 3.1 to 3.3. The second-stage regression results and test results in section 3.4 are obtained via Stata.

\section{Input Oriented VRS SBM}

Results of input-oriented VRS model are shown in Table 2. Those with full efficiency are shown with white cells and shaded cells indicate low efficiency.

Table 2: SBM-I-V Efficiency Score

\begin{tabular}{|l|l|l|l|l|l|l|l|l|}
\hline DMU & 2004 & 2005 & 2006 & 2007 & 2008 & 2009 & 2010 & 2011 \\
\hline Taoyuan & 1 & 1 & 1 & 1 & 1 & 1 & 1 & 1 \\
\hline Kaohsiung & 0.769353 & 0.804921 & 0.763018 & 0.875124 & 1 & 0.753767 & 0.714564 & 0.623997 \\
\hline Songshan & 1 & 1 & 1 & 1 & 1 & 1 & 1 & 1 \\
\hline Hualien & 0.58435 & 0.555488 & 0.479275 & 0.385938 & 0.283289 & 0.19006 & 0.189618 & 0.182221 \\
\hline Taitung & 0.694452 & 0.714841 & 0.697383 & 0.540035 & 0.44977 & 0.534609 & 0.539313 & 0.535436 \\
\hline Magong & 1 & 1 & 1 & 1 & 1 & 1 & 1 & 1 \\
\hline Taichung & 1 & 0.73207 & 0.732061 & 0.634835 & 0.610309 & 0.560486 & 0.639007 & 0.691158 \\
\hline Tainan & 0.799096 & 0.781894 & 0.730039 & 0.447778 & 0.247333 & 0.16782 & 0.163063 & 0.170801 \\
\hline Chiayi & 1 & 1 & 1 & 1 & 0.389674 & 0.425881 & 0.398026 & 0.398361 \\
\hline Qimei & 1 & 1 & 1 & 1 & 1 & 1 & 1 & 1 \\
\hline Wang'an & 1 & 1 & 1 & 1 & 1 & 1 & 1 & 1 \\
\hline Lanyu & 0.819752 & 0.988219 & 1 & 1 & 1 & 1 & 1 & 1 \\
\hline Lyudao & 0.653847 & 0.671599 & 0.653019 & 0.677558 & 0.682305 & 0.651903 & 0.629085 & 0.676846 \\
\hline Kinmen & 1 & 1 & 1 & 1 & 1 & 1 & 1 & 1 \\
\hline Beigan & 1 & 1 & 1 & 0.584962 & 0.599952 & 0.642481 & 0.649289 & 0.663155 \\
\hline Pingtung & 1 & 0.173222 & 0.151087 & 0.135798 & 0.124331 & 0.120765 & 0.122052 & 0.122052 \\
\hline
\end{tabular}

Taoyuan, Songshan, Magong, Qimei, Wang'an and Kinmen are the 6 airports with full efficiency for the entire period. Except for the two capital airports (Taoyuan and Songshan Airports), the rest are all off-shore island airports. Kaohsiung, the second 
biggest airport enjoys a full efficiency in year 2008 but faces decreasing efficiency behave since 2009. Hualien, Taitung, Tainan and Chiayi are the 4 airports confronted with a decreasing in efficiency since 2008. They are all small airports on the main Taiwan island. For the rest, there are no obvious shifts in efficiency. (Turning points for Beigan and Pingtung are due to a big construction and the following increase in input.)

\section{Malmquist Indices}

In Table 3 we see more light area (increasing productivity) on the right-hand side of year 2008 and more dark area (decreasing productivity) on the left-hand side. It shows more clearly that after 2009 almost every airport in Taiwan enjoys an increase in productivity, especially Kaohsiung, Songshan, Magong and Taichung airports, which all have direct flights to China.

Table 3: I-V Malmquist Index

\begin{tabular}{|l|l|l|l|l|l|l|l|}
\hline Malmquist & $04=>05$ & $05=>06$ & $06=>07$ & $07=>08$ & $08=>09$ & $09=>10$ & $10=>11$ \\
\hline Taoyuan & 0.970455 & 1 & 1 & 0.89846 & 1.020901 & 1.063923 & 1 \\
\hline Kaohsiung & 0.966457 & 0.809812 & 0.799871 & 0.698511 & 0.740948 & 1.2323 & 0.996388 \\
\hline Songshan & 0.552371 & 0.603279 & 0.490991 & 0.466601 & 0.835447 & 1.238678 & 1.361529 \\
\hline Hualien & 0.8858 & 0.825454 & 0.804369 & 0.799473 & 0.701664 & 1.029555 & 0.960294 \\
\hline Taitung & 0.949908 & 0.962843 & 0.787122 & 0.872472 & 1.136283 & 1.040366 & 1.02285 \\
\hline Magong & 0.950492 & 1.010626 & 0.97148 & 0.979018 & 0.902955 & 1.274775 & 1.152318 \\
\hline Taichung & 0.690981 & 0.960663 & 0.884156 & 1.043512 & 0.885757 & 1.220758 & 1.114377 \\
\hline Tainan & 0.896155 & 0.909021 & 0.622626 & 0.572991 & 0.716769 & 1.00805 & 1.051322 \\
\hline Chiayi & 0.865841 & 0.91396 & 0.5734 & 0.391761 & 1.06138 & 0.946415 & 1.019584 \\
\hline Qimei & 1.073039 & 1.006904 & 0.994883 & 1.008695 & 1.014983 & 0.978614 & 0.99857 \\
\hline Wang'an & 1.000527 & 1.044849 & 0.994917 & 1.000017 & 1.030529 & 0.97055 & 0.998791 \\
\hline Lanyu & 1.101359 & 1.110826 & 0.997029 & 0.934062 & 1.243842 & 1.144537 & 1.000018 \\
\hline Lyudao & 0.975225 & 1.019262 & 1.049688 & 0.997696 & 1.020449 & 0.948005 & 1.07085 \\
\hline Kinmen & 1.071665 & 0.990474 & 1.148917 & 1.292277 & 1.0934 & 1.064796 & 1.048295 \\
\hline Beigan & 0.730759 & 0.950789 & 0.477362 & 1.036779 & 1.062957 & 1.028248 & 1.016207 \\
\hline Pingtung & 0.15486 & 0.887884 & 0.891436 & 0.92334 & 0.977228 & 0.999884 & 1 \\
\hline Nangan & 0.845858 & 0.867175 & 0.921815 & 1.077861 & 0.984109 & 0.920374 & 1.098163 \\
\hline Hengchun & 0.988481 & 0.997418 & 0.994539 & 0.998913 & 0.997499 & 1.000126 & 0.999767 \\
\hline Average & 0.870568 & 0.937291 & 0.855811 & 0.888469 & 0.968172 & 1.061664 & 1.050518 \\
\hline
\end{tabular}

Among these airports, a special example is Songshan Airport. Being the first airport in Taiwan and the only airport within Taipei city, Songshan Airport used to be the sky gateway into Taiwan until 1979 when Taoyuan International Airport ${ }^{12}$ started operation as one of the "Ten Major Construction Projects" in Taiwan and at the same time

12 Was named as Chiang Kai-shek International Airport from 1979 to 2006. 
replaces Songshan Airport as the only international airport of Taipei. However, thanks to the "Three Link" agreement, Songshan Airport opened its international routes again to Hongqiao Airport of Shanghai in 2010. As part of Taiwanese President Ma Yin-jeou's "Golden Aviation Circle in Northeast Asia" campaign ${ }^{13}$, the flight services between Songshan Airport and Haneda Airport of Tokyo resumed operation in the same year. Moreover, in 2011 the flight service between Songshan Airport and Gimpo Airport of Seoul also started operation. As a result of the newly opened China routes and other northeastern Asian routes, Songshan Airport's decreasing trend due to the declining demand for domestic flights abated in 2009 and since 2010 Songshan Airport embraces strong increase ever since.

\section{Decomposition of Malmquist index}

Figure 5 illustrates the Catch-up Effect, Frontier-shift Effect as well as the Malmquist index of all the airports in the specific period. In the original Malmquist index graph, it looks more like chaos where the increasing trend is not so clear, although we can still tell that more values before the year 2008-2009 is below one while more values afterward is above one.

In the Frontier-shift Effect graph, we could understand this radical change more clearly: almost every DMU has a Frontier-shift Effect value less than one while most of them enjoy a value above one after 2008-2009 period. By contrast, the graph of Catch-up Effect shows a different trend. The values are dispersing before the year 2008-2009, where the smallest value is around 0.2 and the biggest value exceeds 1.2. After the year 2008-2009, however, the values are congregated with a distance around 0.2 between the biggest value and the smallest ones.

\section{Second-Stage Regression}

At this stage, we use regression models to verify the impact of several characteristic factors. At first, we run the following fixed effect, random effect to test the factors affecting airports' DEA efficiency scores:

$$
\mathrm{DEA}_{\mathrm{it}}=\mathrm{X}_{\mathrm{it}} \beta+\alpha_{\mathrm{i}}+\mathrm{U}_{\mathrm{it}}
$$

\footnotetext{
${ }^{13}$ Direct flights from Taipei's Songshan Airport to Seoul's Gimpo Airport to begin in March. Taiwan's president continues to carry out his "golden routes". CNN Travel 15 November 2011 http://travel.cnn.com/seoul/visit/direct-flights-taipeis-songshanairport-seouls-gimpo-airport-begin-march-487057
} 
The $\mathbf{X}_{\text {it }}$ here include the following dummy variables: $\mathrm{CN}$ indicates whether the airport operates a direct China route or not. OFF indicates whether the airport locates on an offshore island (1) or on the main Taiwan Island (0). INT shows at least one international route is connected to this airport and $\mathrm{ML}$ suggests whether the military force also uses this airport. The Mega and Mini variables are used to measure the passenger size of the airport.

Figure 5a: Progression of catch-up effect

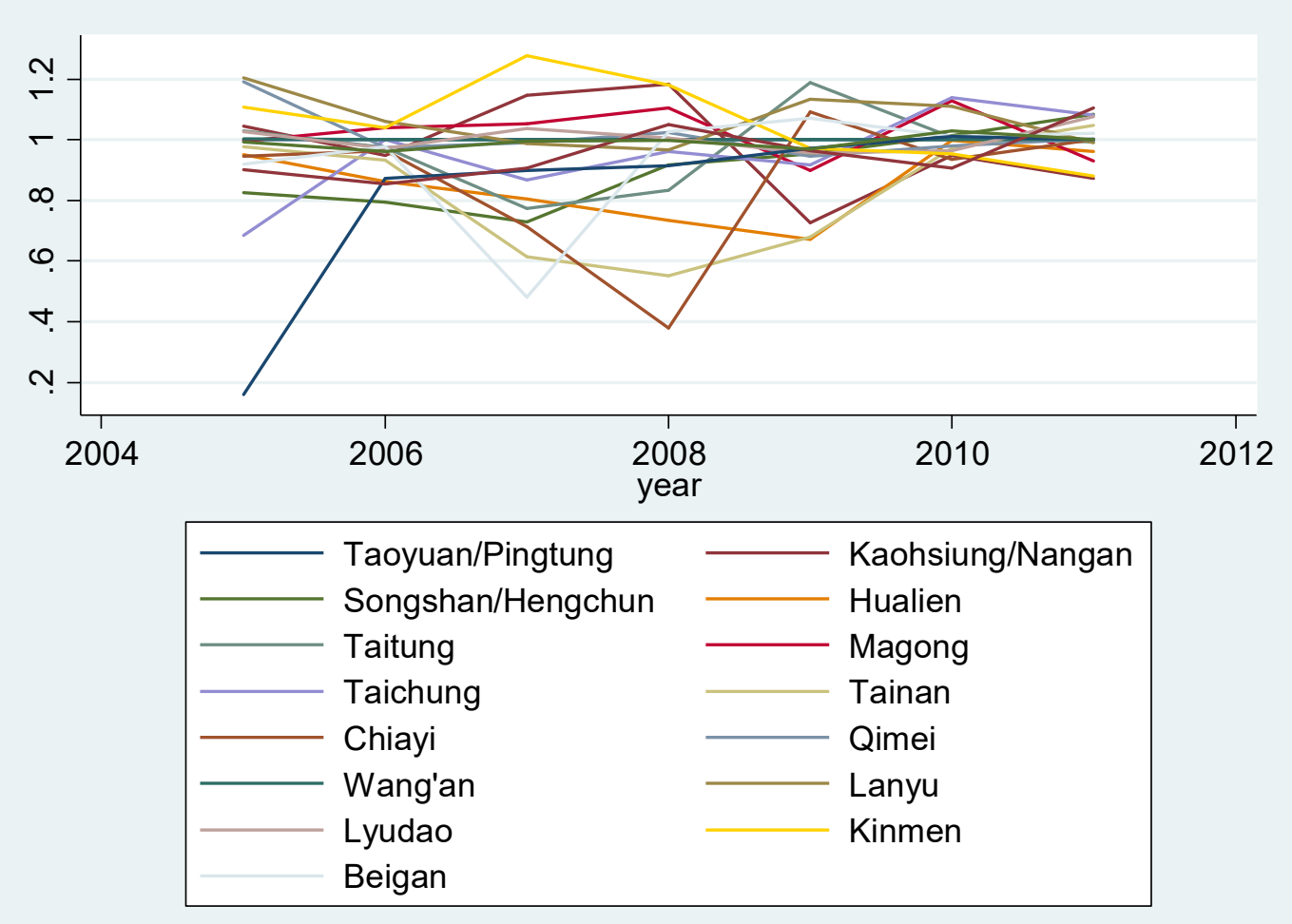

Figure 5b: Progression of frontier-shift effect

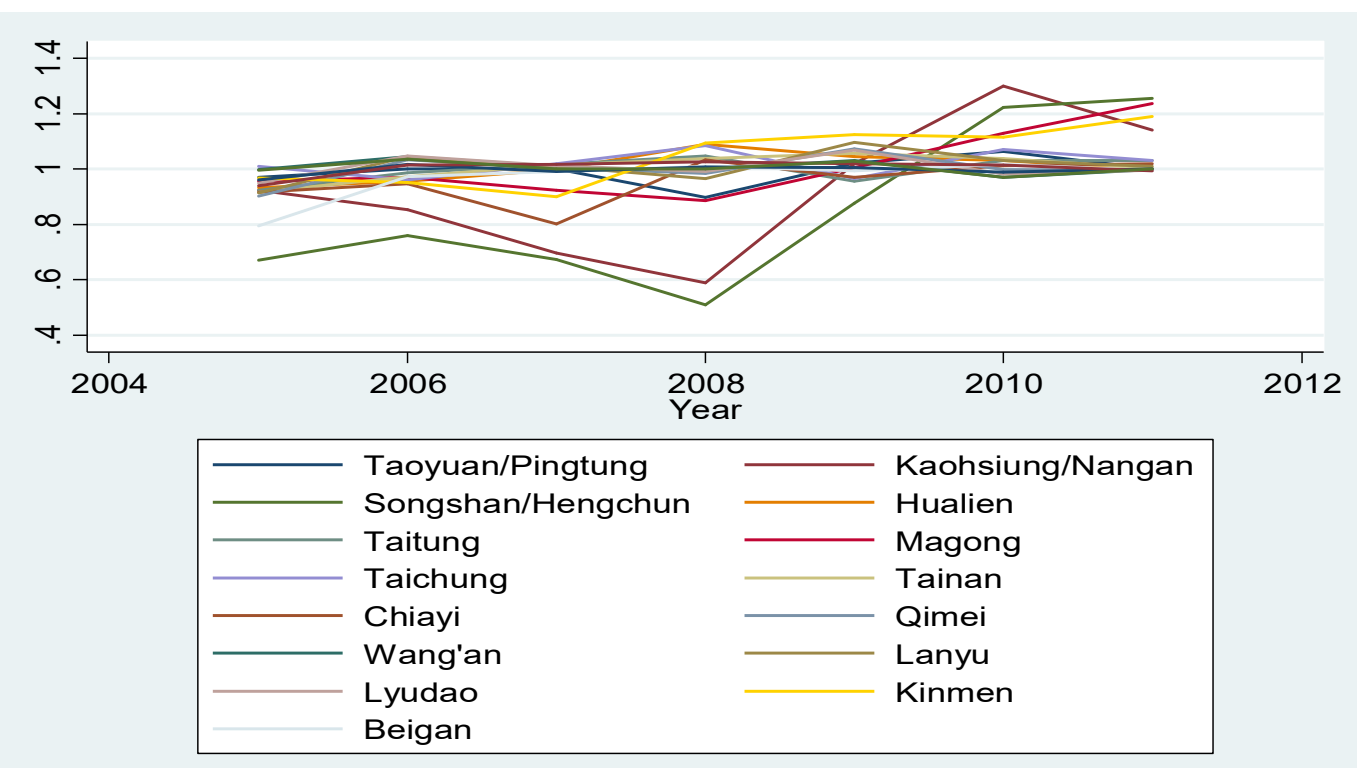


An airport is classified as "Mega" airport if the passenger volume exceeds 10 million and "Mini" airport if its passenger volume is less than one million. In a fixed effects model OFF, ML and Mega are excluded from $\mathbf{X}_{\text {it }}$ because these variables are timeinvariant. Relatively, in a random effects model we could include all these variables with the assumption that $\alpha_{\mathrm{i}}$ is not correlated with $\mathbf{X}_{\mathrm{it}}$. In the Hausman and Taylor model, however, the restriction of no correlation between $\alpha_{\mathrm{i}}$ and $\mathbf{X}_{\mathrm{it}}$ could be relaxed without losing those time-invariant regressors. Hausman Test is applied to verified which regressor is correlated with the individual effect $\alpha_{i}$.

$$
\mathrm{W}=\frac{\left[\widehat{\beta_{\{\mathrm{FE}, \mathrm{k}\}}}-\widehat{\beta_{\{\mathrm{RE}, \mathrm{k}\}}}\right]}{\left[\mathrm{se}\left(\widehat{\beta_{\{\mathrm{FE}, \mathrm{k}\}}}\right)^{2}-\operatorname{se}\left(\widehat{\beta_{\{\mathrm{RE}, \mathrm{k}\}}}\right)^{2}\right]^{\frac{1}{2}}}
$$

The test results for CN, INT and Mini variables are 0.443, -1.175 and 1.529, which all have a p-value larger than 0.05 . The Hausman Test for the overall model shows consistent result of a chi-squared value at 2.52 and a $p$ value at 0.47 . As a result, random effects model is preferred. We list both results in Table 4, with a pooled Simar \& Wilson efficiency analysis model as a reference. In Table 4, we find negative relationship between the DEA efficiency score and the dummy variable $\mathrm{CN}$. This might be an unexpected outcome before further exploring. Table 5 shows us the regression result for Malmquist index. At a significance level of 5\%, the dummy variable $\mathrm{CN}$ has positive impact on the improving of productivity of Taiwanese airports. International route also brings positive effect to Malmquist index, with a larger coefficient and a bit higher significance. On the other side, in pooled OLS and random effect model offshore island airports show a strong positive gap with the airports on the main Taiwan island.

From the regression result of Malmquist index, the airports with a direct China route do increase faster than their counterparts. Why is the $\mathrm{CN}$ variable negatively related with the DEA score then? An overview of the data structure gives us a possible answer. Eight Taiwanese airports were opened from 2009 to Chinese routes. Taoyuan and Kaohsiung are permitted for regular flights while Songshan, Hualien, Taitung, Taichung, Kinmen and Magong are for chartered flights. Although capital airports Taoyuan and Songshan, along with offshore island airports Kinmen and Magong show full efficiency along this period, we should notice that smaller airports in Taiwan island like Hualien, Taitung and Taichung are also appointed to Chinese routes. Although they do show a 
progress in their efficiency, as we observed in the Malmquist index, their absolute values of DEA efficiency scores are lower than their counterparts. In addition, Kaohsiung airport does not seem to be successful even after the agreement. As a result, we see the negative sigh in the regression result of DEA efficiency score.

Table 4: Regression Results for DEA Efficiency Scores

\begin{tabular}{|c|c|c|c|}
\hline & Pooled Simar \& Wilson & Fixed Effect & Random Effect \\
\hline $\mathrm{CN}$ & $\begin{array}{c}-0.1505^{* *} \\
(0.054)\end{array}$ & $\begin{array}{c}-0.0992^{*} \\
(0.016)\end{array}$ & $\begin{array}{l}-0.101^{*} \\
(0.012)\end{array}$ \\
\hline OFF & $\begin{array}{c}0.3065^{* * *} \\
(0.000)\end{array}$ & $\begin{array}{l}0 \\
(.)\end{array}$ & $\begin{array}{l}0.320^{* *} \\
(0.002)\end{array}$ \\
\hline INT & $\begin{array}{c}0.1827^{* * *} \\
(0.051)\end{array}$ & $\begin{array}{l}0.00644 \\
(0.920)\end{array}$ & $\begin{array}{l}0.0334 \\
(0.575)\end{array}$ \\
\hline$M L$ & $\begin{array}{l}-0.0099 \\
(0.046)\end{array}$ & $\begin{array}{l}0 \\
(.)\end{array}$ & $\begin{array}{l}0.0349 \\
(0.737)\end{array}$ \\
\hline Mega & $\begin{array}{l}0 \\
(.)\end{array}$ & $\begin{array}{l}0 \\
(.)\end{array}$ & $\begin{array}{c}0.300 \\
(0.171)\end{array}$ \\
\hline Mini & $\begin{array}{c}-0.2891^{* * *} \\
(0.059)\end{array}$ & $\begin{array}{l}-0.117 \\
(0.175)\end{array}$ & $\begin{array}{c}-0.193^{* *} \\
(0.006)\end{array}$ \\
\hline $\begin{array}{l}\text { Constan } \\
\text { t }\end{array}$ & $\begin{array}{c}0.6593^{* * *} \\
(0.000)\end{array}$ & $\begin{array}{l}0.840^{* * *} \\
(0.000)\end{array}$ & $\begin{array}{l}0.710^{* * *} \\
(0.000)\end{array}$ \\
\hline $\begin{array}{l}\text { Observa } \\
\text { tions }\end{array}$ & 126 & 126 & 126 \\
\hline $\begin{array}{l}\text { Adjuste } \\
\mathrm{d} R^{2} \\
\text { rho }\end{array}$ & 0.467 & $\begin{array}{l}-0.114 \\
0.709\end{array}$ & 0.585 \\
\hline
\end{tabular}

$p$-values in parentheses

${ }^{*} p<0.05,{ }^{* *} p<0.01,{ }^{* * *} p<0.001$

Table 5: Regression Results for Malmquist Index

\begin{tabular}{lccc}
\hline & Pooled & Fixed Effect & Random Effect \\
\hline CN & $0.141^{* * *}$ & $0.142^{* * *}$ & $0.143^{* * *}$ \\
& $(0.001)$ & $(0.001)$ & $(0.000)$ \\
OFF & $0.195^{* * *}$ & 0 & $0.201^{* * *}$ \\
& $(0.000)$ & $()$. & $(0.000)$ \\
INT & $0.0959^{*}$ & $0.200^{* *}$ & $0.112^{*}$
\end{tabular}




\begin{tabular}{lccc} 
ML & 0.0259 & 0 & 0.0219 \\
& $(0.487)$ & $()$. & $(0.635)$ \\
Mega & 0.0716 & 0 & 0.0495 \\
& $(0.349)$ & $()$. & $(0.607)$ \\
Mini & 0.0411 & -0.143 & 0.0277 \\
& $(0.302)$ & $(0.102)$ & $(0.549)$ \\
Constant & $0.765^{* * *}$ & $0.965^{* * *}$ & $0.770^{* * *}$ \\
& $(0.000)$ & $(0.000)$ & $(0.000)$ \\
\hline Observations & 126 & 126 & 126 \\
Adjusted $R^{2}$ & 0.227 & 0.080 & 0.0966 \\
rho & & 0.585 & \\
$\begin{array}{l}p \text {-values in parentheses } \\
{ }^{*} p<0.05,{ }^{* *} p<0.01,{ }^{* * *} p<0.001\end{array}$ &
\end{tabular}

\section{CONCLUSIONS AND FOLLOWING WORK}

According to the results of DEA efficiency scores and Malmquist index, along with the regression result for both of them, we try to shed a light on the effect of direct China routes on the efficiency of Taiwanese airports. As discussed in the previous chapter, China route variable is negatively related to DEA efficiency scores due to the selection of appointed airports. It is likely that economic benefit is not the only reason to open a specific airport. Otherwise, the best strategy would be opening only Taoyuan International Airport in order to support its target to become a hub airport in the AsiaPacific region. The cross-strait relation, as well as the election and politics in Taiwan also played an important role here. On the other hand, the China route variable shows positive effect on Malmquist index. Those assigned airports may be less efficient in the beginning but they are growing faster than others are. After the Three Links agreement, the overall productivity of Taiwanese airports increases but the gap between big airports and small airports in the sense of efficiency also increases.

How to keep the growth of big international airports in the competition with other Asian airports, as well as how to deal with the inefficient small airports without prejudice against local residents are the two important topics facing Taiwan civil aviation authorities. Possible future research would be on: (1) Figure out the reason behind the negative relationship between Chinese routes and Taiwan airports efficiency. (2) Construct an applicable methodology of adopting Assurance Region model in calculating the Malmquist Index. 
As a final remark, we point out that traditionally, Tobit regression was used due to the interval of the DEA scores being between zero and one. However, John McDonald argues that since DEA efficiency score is a fractional data instead of being generated by a censored process, Tobit model may not be appropriate. An ordinary least square is consistent in this situation (McDonald, 2009). Additionally, others argue that a fractional regression model is the best fit for analyzing DEA scores in the second stage (Ramalho, Ramalho, \& Henriques, 2010). Verifying the result of this paper by using fractional regression model would also be a possible following work.

\section{REFERENCES}

Abbott, M., \& Wu, S. (2002). Total factor productivity and efficiency of Australian airports. Australian Economic Review, 35(3), 244-260.

Cooper, W. W., Seiford, L. M., \& Tone, K. (2007). Data envelopment analysis: a comprehensive text with models, applications, references and DEA-solver software: Springer Science \& Business Media.

Fare, R., Grosskopf, S., \& Lovell, C. K. (1994). Production frontiers. Cambridge University Press.

Fung, M. K. Y., Wan, K. K. H., Hui, Y. V., \& Law, J. S. (2008). Productivity changes in Chinese airports 1995-2004. Transportation Research Part E: Logistics and Transportation Review, 44(3), 521-542. doi:10.1016/j.tre.2007.01.003

Liebert, V., \& Niemeier, H.-M. (2013). A survey of empirical research on the productivity and efficiency measurement of airports. Journal of Transport Economics and Policy (JTEP), 4オ(2), 157-189.

Lin, L., \& Hong, C. (2006). Operational performance evaluation of international major airports: An application of data envelopment analysis. Journal of Air Transport Management, 12(6), 342-351.

Malmquist, S. (1953). Index numbers and indifference surfaces. Trabajos de Estadistica $y$ de Investigacion Operativa, 4(2), 209-242.

McDonald, J. (2009). Using least squares and tobit in second stage DEA efficiency analyses. European Journal of Operational Research, 1972), 792-798. doi:10.1016/j.ejor.2008.07.039

Oum, T. H., \& Yu, C. (2004). Measuring airports' operating efficiency: a summary of the 2003 ATRS global airport benchmarking report. Transportation Research Part E: Logistics and Transportation Review, 40(6), 515-532.

Ramalho, E. A., Ramalho, J. J. S., \& Henriques, P. D. (2010). Fractional regression models for second stage DEA efficiency analyses. Journal of Productivity Analysis, 34(3), 239-255. doi:10.1007/s11123-010-0184-0

Tone, K. (2011). Slacks-based measure of efficiency Handbook on data envelopment analysis (pp. 195-209): Springer.

Yang, H.-H. (2010). Measuring the efficiencies of Asia-Pacific international airports Parametric and non-parametric evidence. Computers \& Industrial Engineering, 59(4), 697-702. doi:10.1016/j.cie.2010.07.023

Yoshida, Y., \& Fujimoto, H. (2004). Japanese-airport benchmarking with the DEA and endogenous-weight TFP methods: testing the criticism of overinvestment in Japanese regional airports. Transportation Research Part E: Logistics and Transportation Review, 40(6), 533-546. doi:10.1016/j.tre.2004.08.003 
Yu, M.-M. (2004). Measuring physical efficiency of domestic airports in Taiwan with undesirable outputs and environmental factors. Journal of Air Transport Management, 10(5), 295-303. doi:10.1016/j.jairtraman.2004.04.001

Yu, M.-M. (2010). Capacity efficiency measurement using a three-stage DEA approach: evidence from domestic airports in Taiwan. Transportation Planning and Technology, 33(2), 221-235. doi:10.1080/03081061003643804

Yu, M.-M., Hsu, S.-H., Chang, C.-C., \& Lee, D.-H. (2008). Productivity growth of Taiwan's major domestic airports in the presence of aircraft noise. Transportation Research Part E: Logistics and Transportation Review, 44(3), 543-554. doi:10.1016/j.tre.2007.01.005 